\title{
Emotions and Status Hierarchies
}

\author{
Patrick Durkee \\ The University of Texas at Austin
}

Chapter to appear in:

L. Al-Shawaf \& T. K. Shackelford (Eds.), The oxford handbook of evolution and the emotions. Oxford University Press. 


\begin{abstract}
Emotions define and are defined by status hierarchies. This chapter examines human emotions in relation to hierarchy navigation. Because emotional adaptations evolve in response to selective pressures, I first present evidence supporting the ubiquity of hierarchies and the fitness-relevance of status in the ancestral past. Next, I provide a sketch of the recurrent adaptive challenges likely posed by life within hierarchically organized groups to circumscribe the hierarchy-navigation tasks emotional adaptations are expected to address. I then highlight several emotions - pride, shame, envy, admiration, respect, contempt, anger, and fear-that appear to facilitate hierarchy navigation, review the evidence for their functional design, and explore ways in which relative differences in status may modulate recurring emotional experiences. Finally, I discuss how understanding the interplay between emotions and hierarchy navigation can inform our understanding of broad individual differences.
\end{abstract}

Keywords: hierarchy; status; emotions; individual differences; personality 


\section{Emotions and Status Hierarchies}

Emotions and status hierarchies are deeply intertwined. In a proximate sense, several emotions - such as those labelled pride, shame, admiration, respect, envy, and contempt in our lexicon-demarcate relative differences in status and the resulting hierarchical structure of human social groups (Steckler \& Tracy, 20I4; Van Vugt \& Tybur, 2015; Witkower et al., 2020). Status-relevant information and relative differences in status, in turn, activate and modulate recurring patterns of different emotional experiences in everyday life (van Kleef \& Lange, 2020). The evolution of emotions can be expected to have been partially directed and refined by the recurrent adaptive problems posed by hierarchies throughout our ancestral past (Tooby \& Cosmides, 1990). Moreover, the constellation of human emotions and their influences on group dynamics likely contributed to the evolution of prestigeprocesses that are unique to human status hierarchies (Gervais \& Fessler, 20I6; Henrich \& Gil-White, 200I). Status hierarchies therefore partially define-and are largely defined by-emotions at multiple levels of analysis.

In this chapter, I aim to build upon the growing literature on the evolved functions of emotions and their roles in human status hierarchies (e.g., Steckler \& Tracy, 20I4; Van Vugt \& Tybur, 20I5; Witkower et al., 2020). As does much of the work in this edited volume, I will explore the interplay between status hierarchies and emotions through an adaptationist lens (Al-Shawaf et al., 20I6; Cosmides \& Tooby, 2000; Nesse, 1990; Sznycer, Cosmides, \& Tooby, 2017; Tooby \& Cosmides, 1990). On this view, emotions are superordinate functional mechanisms instantiated in our neurobiology. These emotion adaptations are activated by cues of adaptive problems to coordinate thoughts, motivations, and behaviors in ways that would have led to net fitness gains for our ancestors over deep time.

The functions of emotional adaptations are shaped by ancestrally recurrent challenges (Tooby \& Cosmides, 1990). If status hierarchies reliably exhibited selection pressures on our ancestors throughout human evolution, we should expect that at least some of our emotions function to aid in solving the challenges posed by life in hierarchically organized social groups. Thus, we can reverseengineer the design features of our emotions by reasoning about the specific adaptive challenges posed by hierarchies. Before outlining specific adaptive challenges, examining relevant emotions, and exploring implications for broad individual differences, I will set up the rationale for expecting hierarchy navigation adaptations by summarizing the evidence for the ubiquity of hierarchies and fitness-relevance of status.

\section{The ubiquity of hierarchies and ancestral importance of status}

Two conditions must be met for adaptations designed to facilitate hierarchy navigation to evolve. First, hierarchies and the adaptive challenges they pose must have been recurrent throughout our evolutionary history. Second, relative position within the hierarchy must have been reliably linked to ancestral fitness. In this section, I present an overview of the evidence supporting these prerequisites.

Hierarchies are ubiquitous across the animal kingdom. Group-living species inevitably form hierarchical social groups of varying steepness and complexity, wherein rank is characterized by predictable behavioral patterns of deference, influence, and attention (Boehm, I999; Chase, I974; Franz et al., 2015; Issa et al., I999; Meese \& Ewbank, 1973). Status hierarchies are a universal feature of human social groups in both modern industrialized and small-scale societies (Anderson et al., 2015; Brown, I991; von Rueden et al., 2008) - they likely were throughout our ancestral past as well. In many species, including non-human primates, hierarchical rank (i.e., status) is defined largely by patterns of agonistic aggression, coercion, and threat displays, such that physically formidable individuals who can more effectively inflict costs on group members and withhold resources attain higher status (de Waal, I982; Franz et al., 2015). Because humans possess the cognitive architecture to assort hierarchically based on aggressive formidability (Durkee et al., 2018; Sell et al., 2009; Toscano et al., 2016), threatened or actualized cost infliction could play an analogous role in human status hierarchies in some contexts (Cheng et al., 2013; Cheng, 2020; Durkee et al., 202I). However, theoretical considerations suggest that pure, in-group directed cost infliction is unlikely to lead to status over time because humans can form 
leveling coalitions to depose overly aggressive, undeserving individuals with relative ease (Boehm, I999, 2012; Cheng, 2020; Gintis et al., 2015; Lukaszewski et al., 2016; Wrangham, 202I). The logic of human status allocation instead appears to be driven primarily by social valuation, competence, and prestige-related processes whereby some individuals tolerate others having greater relative access to resources, influence over group outcomes, and attention to the extent that they directly or indirectly generate benefits for others in the group (Chapais, 2015; Durkee et al., 2020; Durkee et al., 202I; Garfield \& Hagen, 2020; Garfield et al., 2019; Garfield et al., 2020; Henrich \& Gil-White, 200I; Redhead et al., 2019). Thus, while human status hierarchies may function somewhat differently than those of non-human animals, they are pervasive - and as I detail below, consequential-features of human groups.

Evidence suggests that status was linked to fitness-relevant outcomes throughout our evolutionary past. In many non-human primate species, status-measured by patterns of grooming and deference-predicts higher fertility and mating success in males, as well as greater offspring survival for females (Cowlishaw \& Dunbar, I991; Majolo et al., 2012). In humans, men's status - as indexed by wealth and political influence-is positively associated with several reproductively relevant outcomes, including surviving offspring, fertility rates, and mating success across 33 non-industrial societies (von Rueden \& Jaeggi, 20I6). Men's status is also associated with other fitness-relevant benefits in small-scale societies, such as privileged access to resources (Patton, 2000), and more allies and cooperative partners (von Rueden et al., 20II; von Rueden et al., 20I9). In studies of a Tsimane forager-horticulturists in the Bolivian Amazon, higher relative wealth was associated with fewer negative health outcomes (Jaeggi et al., 2020), and women with more political influence tended to have healthier children on average (Alami et al., 2020). Even in modern industrialized societies ${ }^{\mathrm{I}}$, where natural fertility is atypical and birthrates are lower than in non-industrialized societies, social status is positively related to proxies of ancestral reproductive success, such as greater mating success, especially for men (de Bruyn et al., 20I2; Hopcroft, 2006, 2015, 202I; Fieder et al., 201I). Taken together, this research demonstrating links between status and fitness across diverse cultures is suggestive that high status bolstered ancestral fitness.

In sum, status hierarchies were likely recurrent and pervasive features of the ancestral social landscape and relative status within these hierarchies likely contributed to fitness throughout our evolutionary past. Given these recurrent selection pressures, we should expect that humans possess psychological adaptations to navigate hierarchies. Consideration of the range of adaptive problems posed by life in hierarchies throughout human evolution may elucidate some of these adaptations.

\section{Adaptive problems posed by life in hierarchically organized social groups}

Because emotions evolved to solve adaptive challenges, it is necessary to detail the array of recurrent adaptive challenges posed by life in hierarchically organized social groups to fully map the constellation of emotions that are functionally intertwined with status hierarchies. In this section, I provide a rough task analysis of the challenges posed by hierarchical social groups that our ancestors would have had to solve to successfully navigate status hierarchies. We can then examine how the characteristics of different emotions might reveal signatures of functional design corresponding to the adaptive challenges of hierarchy navigation.

Defining the adaptive problems associated with hierarchy navigation necessarily involves abstraction and generalization. Just as the boundaries between many psychological entities are "fuzzy" (Del Giudice, this volume; Nesse, 1990), the adaptive challenges of hierarchy navigation are overlapping and cannot be neatly categorized into discrete units. Further, the specific challenges posed by hierarchies cannot be specified for every possible cultural context and every human group; but there are regularities in the types of challenges posed by hierarchies that could be targets for selection to shape functional mechanisms, such as emotions, that overcome them. I aim to detail partially distinct adaptive

\footnotetext{
${ }^{I}$ But note that because the mechanisms that comprise our mind were designed by selection pressures operating over deep time throughout our evolutionary history, status-fitness links need not be present in the modern environment for these mechanisms to be activated (Tooby \& Cosmides, 1990) - only ancestrally relevant cues to challenges associated with hierarchy navigation need be present.
} 
challenges at a level of abstraction applicable to most contexts in which humans have lived throughout evolutionary history. We should not expect that every adaptive challenge will be faced by every individual living in a hierarchy, but rather that likely had to be overcome with enough regularity in the ancestral past such that functional mechanisms designed to solve them should be part of the human species-typical cognitive architecture. Additionally, not every adaptive challenge posed by hierarchies necessitates an evolved emotional response to address it: some may be adequately solved by other classes of adaptations, such as internal regulatory variables or perceptual mechanisms (Tooby et al., 2008). Finally, emotions - let alone their folk labels (c.f., Fiske, 2020)—may not map onto adaptive challenges in a one-to-one manner.

Still, conducting a task analysis of the adaptive challenges posed by hierarchies can guide consolidation of existing evidence for the role of emotions in hierarchy navigation and generate new predictions about their design features. Below, I detail several classes of adaptive challenges posed by hierarchies: pursuing and attaining status, leveraging acquired status for fitness gains, maintaining one's acquired status, mitigating status loss when it occurs, allocating status to others, tracking others' status, interacting with higher status individuals, and hierarchy restructuring or leveling.

Pursuing status. One of the central adaptive problems of hierarchy navigation is pursuing status. This broad challenge encompasses many other, more concrete sub-challenges. These subchallenges include identification and cultivation of status-enhancing characteristics, advertisement of these characteristics, avoidance or concealment of status-decreasing characteristics, and appropriate calibration of motivations for status pursuit.

To pursue status, individuals must identify-consciously or not - the myriad local status criteria and which tactics and strategies can be used to gain status within their local environment (Buss et al., 2020). Individuals must then determine which criteria, tactics, and strategies they can effectively implement in the pursuit of status (Kyl-Heku \& Buss, 1996). This likely requires some degree of selfassessment and comparison to others on status-relevant criteria. Some status criteria are relatively unalterable characteristics (e.g., age, height, being the child of a high-status individual), but many others are less immutable and must be cultivated (e.g., hunting skills, being a reliable group member) or accentuated (e.g., attractiveness). For status criteria that involve social learning (e.g., culturally specific skills), individuals must identify skilled models to learn from or emulate (Henrich \& Gil-White, 20oI). Given that the combinations of status criteria that could be pursued are essentially infinite, individuals must determine how to allocate their limited time and energy in the service of maximizing the qualities they can leverage for status pursuit within the cultural milieu.

Although many acts, characteristics, and events that could enhance status will be readily apparent to others in the group (e.g., physical attractiveness), others may be less apparent (e.g., humor, bravery, prosociality). Individuals may need to advertise status-enhancing personal characteristics to receive commensurate status boosts. In contrast, any of the myriad acts, characteristics, or events that could decrease status may need to be concealed or compensated for to prevent status loss-or, if status loss has already occurred, individuals might need to mitigate further damages (e.g., through appeasement or bargaining; Sznycer, 2019). Moreover, individuals must identify and encode status gains or losses to track their relative position in the hierarchy (Durkee et al., 20I9).

Another sub-problem of status pursuit is that individuals must appropriately calibrate motivations for status pursuit. These motivations need not be consciously represented as desiring status per $\mathrm{se}^{2}$ - they could be represented as motivations to carry out behaviors and pursue goals that were reliably associated with status attainment in the ancestral past (Buss, 1997; Tooby et al., 2008). Because status pursuit is just one of many fundamental motives (Kenrick et al., 20I0), status striving must be calibrated to balance the tradeoffs that accompany effort spent pursuing status with the time and effort needed to address other important adaptive problems, such as maintaining shelter, finding food,

\footnotetext{
${ }^{2}$ While evidence suggests that desiring status and striving for status are fundamental human motives which are consciously represented to some extent (Anderson et al., 20I5; Kenrick et al., 20IO; Ko et al., 2020), many more motives that are not represented as status motives may ultimately serve status pursuit.
} 
acquiring mates, parenting, and mate retention. Although status attainment may further other fundamental motives (e.g., acquiring mates) and status pursuit may be furthered by successfully solving other adaptive problems (e.g., being good at finding food), the appropriate ratio of status-striving relative to other activities must be judiciously allocated, given finite time and energy budgets. The ideal calibration may differ predictably between individuals as a function of individual difference variables (e.g., sex, age, physical attractiveness) and socio-ecologies (e.g., hierarchy steepness, mating system, food abundance), as well as across development as costs and benefits of pursuing different goals change.

Leveraging status. In tandem with status pursuit and attainment, individuals living in hierarchically organized groups face the challenge of efficiently leveraging acquired status to harvest the associated benefits, such as increased access to resources or control over group decisions. This adaptive challenge may solve itself to the extent that one's status is derived from others' perceptions of value as a generator of positive externalities or as a skilled cultural model (Henrich \& Gil-White, 200I; Henrich et al., 20I5). In such cases, lower-status individuals might be motivated to bestow benefits on higher-status, skilled models or producers as an investment in greater future returns on valuable resources, to foster a relationship in which they can efficiently learn status-relevant skills, or to receive other incidental benefits. Still, each individual within the group could benefit by free riding on positive externalities without providing respect, deference, or allowing higher-status individuals priority access to resources (Price \& Van Vugt, 20I4). Consequently, higher status individuals may sometimes need to solve the challenge of incentivizing deference from others-possibly by threatening or actuating benefit withdrawal or cost infliction. To facilitate bargaining for the benefits associated with higher status, status gains may require upregulating internal estimates of the respect, deference, and favorable treatment one is entitled to from others, as well as recruitment of allies to further increase one's coalitional bargaining power.

Maintaining status. In addition to pursuing and leveraging status, maintaining status is also a partially distinct adaptive challenge. At minimum, solving this adaptive challenge likely requires continuing to develop and display any skills or qualities necessary to continue to generate the benefits that are relevant to one's status attainment. The maintenance of status also likely requires the continued avoidance or concealment of acts, characteristics, and events that would diminish one's status (Sznycer, 2019). The challenge of maintaining status is complicated by the challenge of leveraging status, since withholding benefits, hoarding resources, being too controlling, or inflicting costs in too self-interested a manner may damage one's status in the long run (Gintis et al., 2015; Wrangham, 202I). Moreover, because others in the group are likely to be competitors for the same status niche, maintaining one's status requires identifying potential rivals and finding ways to outcompete them, when necessary (Hill \& Buss, 2008). This adaptive challenge is likely more salient if one's status is derived from generating benefits for only a minority of group members, rather than the entire group-unless the group of coalitional allies one is generating benefits for is so formidable that they can stave off leveling attempts from the larger group (Mead \& Maner, 2012; Durkee et al., 202I). In either case, maintaining status without generating commensurate benefits likely requires greater energy and time expenditures to deal with competitors and leveling coalitions.

Mitigating status loss. An inevitable challenge faced by individuals living in hierarchically organized groups is status loss. History is replete with high status individuals suffering devastating falls from grace. While the vast majority of people are not likely to experience such extreme status swings, the status of most individuals is in constant negotiation resulting in frequent ups and downs, so some degree of at least temporary status loss over one's lifetime is likely.

Many factors can bring about status loss (Buss et al., 2020). Individuals' can experience status loss when previously concealed status-damaging characteristics come to light, when they fail to generate benefits that their status depends on, when rivals outcompete them in status-relevant domains, when moving to a new group changes their relative value in status-relevant domains, when they are deposed 
by a leveling coalition for hoarding too many resources or inflicting too many costs, and when a mating relationship or friendship that provided status via the mate's or friends' status ends.

Status loss triggers a cascade of adaptive challenges, the scale and specifics of which will often depend on the particular reason for status loss and the amount of status loss. At a minimum, status loss is likely to entail a commensurate loss of influence and access to resources, which may need to be supplemented. Status damage may also lead to loss of coalitional allies, friends, mates, and even kin support (von Rueden et al., 20I9). In the extreme, complete loss of respect can result in being exiled from one's community, which would likely be detrimental to survival and reproductive success in most contexts throughout human evolution (Buss, 1990). When status is lost, individuals must recalibrate internal estimates of entitlement downward in accordance with the degree of status loss to appropriately interact with others; other internal estimates of one's standing on socially relevant traits that partially depend on status - such as mate value - may need to be recalibrated as well. Alternatively, if individuals attempt to mitigate status loss by bargaining or making consolations to regain their relative standing, they must determine effective negotiation strategies (Kyl-Heku \& Buss, 1996).

Allocating and tracking status. Another set of challenges associated with life in hierarchically organized groups is allocating status to others and tracking others' relative status. Status allocation is an adaptive challenge because the relative differences in respect, attention, and influence that emerge from status distribution will partially define one's own relative access to resources, as well as group outcomes (Buss et al., 2020; Henrich \& Gil-White, 200I). Individuals must then allocate status sparingly, directing it towards individuals who would generate benefits with their greater relative influence, and withholding it from those who would fail to do so. As with status pursuit, status allocation subsumes the challenge of identifying personal characteristics that are valuable within the local ecology; however, in this case, individuals must apply (implicit or explicit) knowledge of these criteria to determine to whom to allocate status, and to track the status of others. Tracking others' status likely also depends on tracking indicators of the extent to which others in the group have allocated status to everyone else, using cues such as patterns of deference and emulation, coalitional networks, and apparent access to resources.

Knowing where others stand in the hierarchy relative to oneself-as well as how strong their status motivations are-is necessary to coordinate interactions with others and behavioral tactics in ways that are appropriate based on relative differences in hierarchical rank (Kyl-Heku \& Buss, 1996) and to avoid the costs of over-estimating one's own status (Anderson et al., 2006). What constitutes situationally appropriate behaviors, however, depends on a wealth of contextual information (Lukaszewski et al., 2020). Thus, in addition to tracking current status rankings and motivations, individuals may need to store and reference past rankings and reasons for changes in status, as well as make forecasts of the likely status trajectories of others in the group-such as younger individuals who may become competitors or potential allies.

Interacting with higher status individuals. As hinted above, appropriately interacting with others based on their relative status is another partially distinct adaptive challenge associated with life in hierarchically organized groups. Higher status individuals, in consequence of their greater influence and respect within group, will possess greater relative control over the flow of benefits and costs within the group (Cheng et al., 2013; Lukaszewski et al., 2016; Maner \& Mead, 20IO; von Rueden, 20I4). It could therefore pay to interact with high-status individuals in ways that could lead to benefits being directed to the self-or to cooperative partners and kin-to improve one's inclusive fitness. Conversely, it could be detrimental to an one's fitness if an interaction with a higher status other made it more likely that benefits would be directed away from-or costs inflicted on - the self or those within one's sphere of inclusive fitness. It is therefore sometimes necessary to produce deference to higher status individuals, even in conflicts of interest, to avoid cost infliction or benefit withdrawal and maximize net fitness in the long term. Moreover, to the extent that higher status individuals attained their status by acquiring learnable or practicable traits and skills, they could be a cultural model to learn from to enhance one's own status, but deference or ingratiation may be necessary to gain and maintain access to the model (Henrich \& Gil-White, 200I). Coordinating thoughts, attention, and behaviors to take advantage of 
potential learning opportunities, curry favor with higher status individuals, and avoid cost infliction is therefore an important adaptive challenge.

Hierarchy restructuring and leveling. Because status hierarchies partially define access to resources within a group, humans living in such groups also face the adaptive challenge of structuring the hierarchy in self-beneficial ways when possible-or at least restructuring the hierarchy when necessary, to avoid detrimental fitness outcomes (Cheng, 2020; Gintis et al., 2015; Lukaszewski et al., 2016). Specifically, if the ratio of costs inflicted to benefits generated flowing downwards from higherstatus individuals to lower-status individuals is tipped too far in the cost infliction direction, it would no longer benefit individuals in the group to defer to or allow the higher-status individuals to influence group outcomes. This adaptive problem could be solved by lower status individuals if they form a leveling coalition that has collectively greater formidability than the cost-inflicting higher status individuals. To solve the challenge of restructuring the hierarchy, it is necessary to solve the subchallenges posed by alliance formation and associated collective action problems (van Schaik et al., 2006; Wiessner, 2019). Moreover, because higher status individuals may place barriers to restructuring or leveling to maintain their status (Case \& Maner, 20I4), individuals seeking to subvert or reform the hierarchy would have to overcome these barriers as well.

\section{Emotions associated with adaptive problems posed by hierarchies}

Because of the fitness-consequences of status and the array of recurrent adaptive challenges posed by hierarchies, the human mind should be equipped with a collection of functional mechanisms, designed through selection, to aid in hierarchy navigation (Kyl-Heku \& Buss, 1996; Tooby \& Cosmides, 1990). In this section, I single out several emotions that appear to either directly support hierarchy navigation or, more simply, are likely to be activated by the adaptive challenges associated with hierarchies: pride, shame, envy, admiration, respect, contempt, anger, and fear. These are by no means the only emotions that can be expected to be related to hierarchy navigation, but they provide enough breadth to explore the functional interconnectedness of hierarchies and emotions for the purposes of this chapter ${ }^{3}$. Table I provides an overview of how each emotion may facilitate hierarchy navigation.

After examining the potential roles of each emotion in hierarchy navigation, I will also explore predictions about individual differences in each emotion as a function of relative status and vice-versa, given their design features. To do so, it will be useful to distinguish predictions about thresholds and frequencies of emotion activation. I will use thresholds to refer to the minimal value of an eliciting-cue that can activate a given emotion. I will use frequencies (or average levels) to refer specifically to the extent to which an emotion is activated or experienced across situations. Although these parameters can be expected to covary, there is utility in distinguishing between them because they can produce differentsometimes conflicting - predictions about individual differences in emotional experience as a function of relative status within a hierarchy.

Pride. The features of pride appear well-designed to aid in solving several problems of status pursuit. Across cultures, pride is activated in response to various personal characteristics in near perfect correspondence with the degree to which those personal characteristics are valued in ego's culture (Cohen et al., 2020; Sznycer, Al-Shawaf, et al., 2017; Sznycer, Xygalatas, Alami, et al., 20I8; Sznycer \& Lukaszewski, 2019), as well as the status-impacts of those personal characteristics (Durkee et al., 2019). Thus, pride can aid in solving the problem of identifying and encoding status-enhancing acts, characteristics, and events. The activation of pride is often accompanied by a species-typical nonverbal display that is characterized by an expansive posture upward-tilted head, and audience-directed gaze (Tracy \& Robins, 2007; Tracy \& Matsumoto, 2008). This nonverbal display is recognized cross-culturally

\footnotetext{
${ }^{3}$ For alternative perspectives and additional discussion pertaining to the hierarchy-relevance of these and other emotions (e.g., social anxiety, sadness, disgust), see: Buss, I990; Gilbert, 200I; Steckler \& Tracy, 20I4; Witkower et al., 2020; van Kleefe \& Lange, 2020.
} 
and is interpreted as a cue of higher status (Shariff \& Tracy, 2009; Shariff et al., 2012; Tracy \& Robins, 2008; Tracy et al, 2013), suggesting that the pride display may be designed specifically to signal status increases to others. The pleasurable experience of pride - and the forecasting of this experience-may also serve to motivate the attainment or pursuit of status-enhancing characteristics. Finally, pride appears to make behaviors that would facilitate status pursuit and maintenance-such as demanding better treatment, spreading information about the pride-inducing event, investing further in prideinducing skills-more likely (Sznycer \& Cohen, 202I).

Given these design features, several predictions can be generated regarding the impact of relative differences in status on individual differences in pride experiences. Most clearly, high status individuals can be expected to have higher frequencies or average levels of pride experiences than lower status individuals. This more frequent pride may partially explain higher status individuals' relatively stronger status motive (Anderson et al., 2020). Moreover, to the extent that elevated pride levels are accompanied by more frequent or conspicuous pride displays, higher status may be associated with increased signaling of hierarchical rank to reinforce status differentials. Conversely, pride thresholds may be lower at lower levels of the hierarchy to facilitate pursuing status and advertising status gains, to the extent that these behaviors are more crucial for lower ranking individuals.

Shame. In many ways, the design features of shame are antithetical to those of pride-but they are functionally suited to solve different adaptive problems. The amount of shame people across cultures expect to feel in response to different personal characteristics being true of them increases in close proportion to the degree to which those personal characteristics decrease their social value and status in the eyes of others in their local communities (Durkee et al., 2019; Cohen et al., 2020; Sznycer, Tooby, et al., 2016; Sznycer, Xygalatas, Agey, et al., 20I8; Sznycer \& Lukaszewski, 2019). This suggests that shame may aid in hierarchy navigation by forecasting negative consequences of personal characteristics to facilitate preemptive avoidance or concealment of those traits. Interestingly, shame is even activated by devaluation that is not due to any explicit wrongdoing, demonstrating that shame is principally concerned with peer valuations rather than the valuation one may feel is deserved (Robertson et al., 2018). Shame experiences are often accompanied by a nonverbal postural display characterized by a downward gaze and slumped posture (Tracy \& Matsumoto, 2008). Viewers of shame displays automatically interpret it as a cue to the displayer's low status (Shariff et al., 20I2). Displaying shame also functions to elicit forgiveness and submission, as is interpreted by viewers as conveying remorse, withdrawal, and willingness to placate, which may help to mitigate further costs of status loss (Keltner 1995; Keltner \& Harker, 1998; Keltner et al., 1997; Martens et al., 2012).

Because the features of shame are relevant for solving adaptive challenges at all levels of the hierarchy - namely those related to preventing and mitigating status loss - the expectations about how relative rank is related to shame are somewhat complicated. Lower status individuals may be more likely to experience shame more frequently, because they are more likely to experience devaluation by others in the group. However, since avoiding or concealing status-decreasing events and characteristics is crucial for maintaining status as well, higher status individuals may experience more preemptive, forecasted shame to facilitate status maintenance. Moreover, it is possible that individuals with lower thresholds for shame activation are better able to navigate status hierarchies and attain higher status, which would also suggest that higher status individuals would (preemptively) experience shame more frequently by virtue of lower thresholds for shame activation, which facilitates forecasting the status impacts of behaviors or the concealment of status-decreasing characteristics. On the other hand, one of the benefits of higher status may be increased buffering from the costs of devaluation; if shame thresholds can change as a function of current status, then this buffering from devaluation may reduce shame sensitivity and make shame experiences less common at higher status levels. Likewise, if people with fewer devalued characteristics are simply more likely to gain status, then higher status individuals may experience shame less frequently, regardless of their shame thresholds. 
Envy. The characteristics of envy appear to facilitate comparison and direct competition with others in the service of increasing ego's relative status (Hill \& Buss, 2006). Envy ${ }^{4}$ is aroused in response to the perceived advantage of a competitor relative to the self (Miceli \& Castelfranchi, 2007; Parrott \& Smith, 1993; Smith \& Kim, 2007). The experience of envy is associated with brain-activation patterns similar to those seen when experiencing physical pain (Takahashi et al., 2009), and with motivations to alleviate the painful envious feelings (Cohen-Charash \& Larson, 20I7). These motivations are accompanied by thoughts of inferiority, as well as hostile and spiteful intentions (Miceli \& Castelfranchi, 2007; Smith \& Kim, 2007), which do not necessarily translate into hostile, spiteful actions (Hill \& Buss, 2008). The outputs of envy fall into strategies of competitor-derogation and self-promotion (Crusius et al., 2020). Unfortunately, most empirical work on the outputs of envy is focused on professional workplace contexts (e.g., Schaubroeck \& Lam, 2004; Moran \& Schweitzer, 2008), so it is unclear how variable and effective the specific outputs of envy are across contexts. The outputs of envy, like all emotions, should be sensitive to contextual cues relevant for determining effectiveness of tactical outputs (Lukaszewski et al., 2020). There does not appear to be nonverbal displays reliably associated with envy (Witkower et al., 2020). The absence of an envy display may be a design feature of envy because displayed envy would be an indication of a perceived status differential, and that a leveling attempt may occur (Hill \& Buss, 2008). Concealing the presence of envy may facilitate success in closing the perceived status gap by not alerting the competitor and by concealing the perceived status differential from others who may not perceive it.

These design features lead to several predictions about the relationship between relative status and individual differences in envy. First, all else equal, higher status individuals can be predicted to experience less envy than lower status individuals, given that lower status individuals should have more higher-status targets to direct envy towards. If the salience or frequency of direct competition increases at higher rungs of the hierarchy, however, it may be that higher status individuals feel envy more frequently or more strongly than lower status individuals. Relatedly, the threshold for envy may change depending on relative status and the number of competitors with similar status levels, such that envy is triggered more easily if there are more potential competitors.

Admiration and respect. Several challenges of hierarchy navigation may jointly or independently be solved by admiration and respect. Admiration and respect are elicited by perceptions of another's competence and warmth (Fiske, 2015; Li \& Fischer, 2007; Wojciszke et al., 2009). Because competence and prosociality are both determinants of status (Durkee et al., 2020), the activation of admiration and respect can facilitate the recognition of status-enhancing characteristics, and upregulation of their status within ego's mind. Respect can also aid in solving the challenge of deferring to higher status others in conflicts of interest, because respect entails a willingness to defer (Wojciszke et al., 2009). Although admiration may share many of the basic features of respect, admiration appears to also specifically involve ingratiation with competent, skilled others in a way that could facilitate learning of the status-relevant skill (Onu et al., 2015); this feature may aid in meeting the challenge of acquiring culturally valued competencies and characteristics. Thus, while the terms admiration and respect are often used interchangeably in the folk lexicon, they may describe multiple emotion programs that solve distinct challenges of hierarchy navigation. Additional empirical research is needed to further investigate these distinct psychological entities.

Admiration and respect experiences can also be predicted to vary in frequency and intensity as a function of relative status. Respect, for instance, may be activated more frequently in individuals lower in the hierarchy, to facilitate deference in return for any benefits generated by higher status individuals. Higher status individuals may less frequently feel respect towards lower status individuals - aside from perhaps baseline recognition of others' intrinsic value. To the extent that admiration differs from respect

\footnotetext{
${ }^{4}$ I note that some theories of envy distinguish benign and malicious envy. But the degree to which these distinctions represent different manifestations of a singular envy program or distinct emotional programs selected for by natural selection to solve different adaptive problems remains unclear. For a thorough review of differences unitary versus dual models of envy, see Crusius et al., 2020.
} 
in being geared specifically towards emulating and learning from skilled cultures models, it can be expected to be felt more frequently by lower status individuals towards higher status individuals. Likewise, admiration experiences should be more common as one is pursuing status through the development of culturally relevant skills-becoming less common once high skill, and putatively higher status, has been attained. Further, frequencies of admiration should also depend more on individual differences in status motivations and be more narrowly targeted at higher-status individuals who possess skills or characteristics that are relevant to the niche in which the admirer is pursuing status, whereas respect should not necessarily depend on status motivations but rather on recognition of others' higher status or valuable qualities.

Contempt. The characteristics of contempt appear to facilitate hierarchy navigation via distancing from low relational value others, exclusion of contemptuous individuals from social networks, and reinforcement of status differentials. Contemptuous feelings are elicited by incompetence (Hutcherson \& Gross, 20II) and violations of social or moral obligations (Fischer \& GinerSorolla, 2016; Rozin et al., I999), which decrease status across cultures (Buss et al., 2020; Durkee et al., 2020). When people feel contempt, they tend to derogate and socially exclude the targeted individual, which contributes to the deterioration of any relationship between the involved parties (Fischer \& Roseman, 2007). A nonverbal facial expression defined by the raising of one-corner of the upper lip (i.e., the unilateral lip curl) often accompanies contemptuous feelings (Ekman \& Friesen, 1986; Matsumoto \& Ekman, 2004; Fischer \& Giner-Sorolla, 20I6). But the unilateral lip curl is often perceived as anger or disgust by viewers cross-culturally ${ }^{5}$, which casts doubt on the specific communicative function of contempt expressions (for review, see Matsumoto \& Ekman, 2004; Fischer \& Giner-Sorolla, 2016).

Given the apparent functional characteristics of contempt, individual differences in manifest contempt can be expected to be defined by relative differences in hierarchical rank. Because contempt is targeted at individuals who are perceived to be low in social value (Gervais \& Fessler, 20I7), higherstatus individuals can be predicted to experience contempt more frequently than lower-status individuals to the extent that they perceive low-status individuals to be low in cooperative value. Similarly, higher relative status may be associated with lower contempt thresholds in order to facilitate cold indifference to, or avoidance of, individuals who are lower status to facilitate the reservation of time and energy budgets for cooperative endeavors with higher status. On the other hand, lower status individuals could also be predicted to frequently experience contempt towards higher status others in contexts where higher status individuals are failing to generate the benefits that their status is derived from-or worse, using their greater relative control to directly inflict costs on lower status individuals in a self-interested manner.

Anger. Although anger is unlikely to be designed specifically to facilitate hierarchy navigation, it can be expected to be elicited by many adaptive challenges posed by hierarchies. According to the recalibrational theory of anger (Sell et al. 2009), anger is designed to motivate bargaining for better treatment from conspecifics. In support of this theoretical account, anger is reliably activated by cues that ego is being undervalued (Sznycer \& Lukaszewski, 2019). The intensity of anger in a given situation is sensitive to a variety of relevant contextual details, such as the intent and motivations of the transgressor (Sell et al., 2017), the relative bargaining power between ego and the transgressor (Sell et al., 2009). The facial expression that often accompanies anger is recognized cross-culturally, communicates the angered individual's intent to bargain for better treatment, and may be designed to signal one's ability to effectively bargain using aggression (i.e., physical formidability; Sell et al., 20I4).

\footnotetext{
${ }^{5}$ These inconsistencies in how contempt manifests may suggest that the psychological phenomena captured by "contempt" and its synonymous folk labels (e.g., scorn, disdain, disregard) could be more accurately characterized as a sentiment (i.e., a network of emotions connected by an attitude; Gervais \& Fessler, 2017). More research is needed to pinpoint what type (or types) of psychological entities are captured by lexical labels of contempt and detail their design features.
} 
An appreciation of the anger program's design features leads to the expectation that anger will be reliably activated by several aspects of hierarchy navigation - and may play a role in solving them. For instance, anger could be expected to play a role in extracting the benefits of status, such as preferential treatment and priority access to contested resources. If one's treatment by another individual is below what might be entitled by one's relative status, the outputs of anger can play a role in recalibrating the target's self-directed welfare-tradeoff ratio in the future-allowing higher status individuals to maximize the benefits of status going forward. In contrast, recognition that another individual perceives themselves to be entitled to more favorable treatment or access to resources than is commensurate with their status, the activation of anger can serve to downwardly calibrate the targets perceptions of entitlement to more closely match ego's estimation of the individual's entitlement. These anger-based negotiations between individuals may function to partially define and regulate relative differences in status. On the more extreme end, the advertisement and recognition of collective anger among multiple members of a group is likely a crucial component of forming leveling coalitions.

Several interesting relationships between individual differences in anger and relative status can be predicted. For one, because any given higher status individual will tend to have greater relative bargaining power than any given lower status individual-by virtue of greater control over resources, access to resources, or coalitional allies-they can be expected to more effectively leverage anger to recalibrate perceived undervaluation (Sell et al., 2009). Thus, it could be predicted that, all else equal, higher status individuals will have lower thresholds for anger and be less likely to inhibit their anger than lower status individuals. To the extent that higher status individuals are genuinely valued by group members, however, lower status individuals may less frequently engage in actions that would anger higher-status individuals (e.g., challenging them for greater share of resources) such that the observable association between relative status and anger frequency across situations is negative or null. The relationship between status and average anger-levels or frequencies of anger experiences could also be negative if lower status individuals are (implicitly or explicitly) aware of the greater anger-proneness of higher status individuals - as well as the greater costs they could inflict — and thus avoid doing things that could anger them. To complicate matters further, the expression of anger may depend on status, such that higher status individuals have greater freedom to express anger than lower status individuals (van Kleefe \& Lange, 2020), and relationship is likely to be somewhat dependent on cultural norms about expression (Park et al., 2013) - this discrepancy between anger experience and anger expression highlights the need to more closely examine anger thresholds in order to understand how status differences interact with the design features of anger.

Fear. The design features of fear may be involved in hierarchy navigation by guiding interactions to avoid cost-infliction from higher status others. Fear is activated by many cues of ancestrally relevant threats to survival, ranging from snakes, spiders and heights to social exclusion, foreboding strangers, and outgroup members (Cosmides \& Tooby, 2000; Öhman \& Mineka, 200I, 2003). The activation of fear, in turn, promotes contextually sensitive behaviors designed to alleviate the harm potentiated by the survival threat, such as increased vigilance, avoidance, escape, and freezing behaviors (Lerner \& Keltner, 200I; Maner et al., 2005). Fear in social situations is also related to conformity to avoid costs (Griskevicius et al., 2006). The species-typical fear expression is universally recognized (Boucher \& Carlson, 1980; Tracy \& Robins, 2008). The fearful face appears to be functionally designed to enhance visual perception (Susskind et al., 2008), and may also function to alert others to impending danger (Reed, \& DeScioli, 20I7; Whalen et al., 200I) and elicit social support (Marsh et al., 2005; Marsh \& Ambady, 2007). To the extent that fear expressions are interpreted by others as signals of subordination, fear may also aid in solving the adaptive challenge of submitting to higher-status others and ceding in agnostic status contests (Steckler \& Tracy, 20I4; Witkower et al., 2020).

Relative differences in rank can be expected to define a great deal of variance in fear experiences within groups. For instance, because higher status individuals can withdraw benefits and inflict costs on lower status individuals with a greater degree of impunity, lower status individuals can be predicted to experience more fear of higher status individuals than vice-versa. This could be driven by lower fear thresholds in lower status individuals or by more frequently experiencing threatened cost infliction. In 
most cases, however, fear in hierarchies may not look like the paralyzing fear associated with immediate survival threats. Instead, fear towards higher-status others may tend to manifest as perceptions of the higher-status other as intimidating, a hesitancy to approach higher-status others without good reason, and heightened caution when interacting with higher-status others-especially in direct conflicts of interest. Contrasting with these predictions, higher status individuals can be expected to experience fear that is caused by same- and lower-status individuals as well. For example, higher-status individuals may experience (preemptive) fear when considering the probability of a leveling coalition, or when spotting envy in competitors, in order to avoid the cost infliction that may be directed their way.

\section{Hierarchy navigation, emotions, and broad individual differences}

Thus far, I have outlined an array of adaptive challenges that are posed by hierarchies and the network of emotions that may be designed to overcome them-or more simply, be reliably activated by them. It is clear that hierarchies and the adaptive challenges they pose can be expected to define much of individuals' emotional experience and content in everyday life. Here, I will briefly consider how further study of the interplay between hierarchy navigation and emotions may also inform our understanding of broad individual differences, such as personality traits.

Thoughts, feelings, and behaviors are the basic elements of personality (Mischel \& Shoda, 1995). Thus, if we want to understand and explain the psychological underpinnings of personality traits and their development over time, it would be helpful to understand the design of emotion programs and how their input-output structure can produce reliably varying individual differences in thoughts, feelings, and behavior (Lukaszewski et al., 2020; Lukaszewski, 202I). Given that hierarchy navigation and relative differences in status can be expected to explain much of the manifest variation in emotional expression, both inter-individually and intra-individually across time, the patterns of variation captured by broad personality taxonomies - such as the Big 5 (Digman, I990; McCrae \& Costa, 1987) and the HEXACO (Lee \& Ashton, 2004) — can be expected to partially defined by the outputs of emotions that are activated by the adaptive challenges of hierarchy navigation.

Understanding whether and how individual differences in emotional experiences arise from hierarchy navigation and relative differences in status may therefore be useful in explaining personality variation. For instance, the personality trait Agreeableness appears to be capturing outputs of the anger program such that people more prone to anger are perceived as less Agreeable (Lukaszewski et al., 2020). Thus, understanding how relative status may alter anger thresholds and frequency of anger experiences can help to explain manifest differences in Agreeableness between individuals, as well as within individuals as they change in status. Similarly, the interindividual variation in shame, pride, and envy thresholds and frequencies - which can arise from many factors, such as genetic mutations that add noise to emotion systems, varying (mis)perceptions of the status impacts of behaviors, different calibrations of status-striving motivations, and existing relative status differences-may help to explain variation along other broad, emergent personality dimensions, such as Honesty-Humility, Extraversion, Conscientiousness. Although emotions guide hierarchy navigation, manifest differences in personality also influence the status that individuals attain (Anderson et al., 200I; Cheng et al., 20I0; Grosz et al., 2020), so there likely exist feedback loops between hierarchical rank, emotion parameters, and personality. At an even broader level, the variety of status niches-and the unique combinations of traits that are most status-relevant within them-may partially define the patterns of trait covariation at the population level and manifest differences in personality structure across populations (see Durkee et al., 2020; Gurven et al., 2013; Lukaszewski et al., 20I7; Smaldino et al., 2019). Finally, further exploration of how hierarchical structure modulates emotions can also facilitate the explanation cross-cultural differences in emotional qualia and folk-affective concepts (Gervais \& Fessler, 20I7).

\section{Conclusion}

This chapter explored the inextricable links between emotions and status hierarchies. The ubiquity of status hierarchies and fitness-relevance of status suggest that humans should possess 
psychological adaptations - such as emotions - for navigating hierarchies. To identify and understand these emotional adaptations, it will be helpful to fully map the numerous and specific adaptive challenges posed by life in hierarchically organized social groups and detail the subtasks required to overcome them. This endeavor has the potential to not only improve our understanding of emotions, but also to reveal how broad patterns of individual and cultural variation may arise from species-typical adaptations for navigating the adaptive challenges posed by status hierarchies.

Acknowledgements: I thank David Buss, Courtney Crosby, Anna Sedlacek, Rebecka Hahnel-Peeters, Kendall Baker, and members of the Center for the Study of Human Nature (CSHN) for constructive feedback. 


\section{References}

Alami, S., Von Rueden, C., Seabright, E., Kraft, T. S., Blackwell, A. D., Stieglitz, J., ... \& Gurven, M. (2020). Mother's social status is associated with child health in a horticulturalist population. Proceedings of the Royal Society $B, 287$ (1922), 20192783.

Al-Shawaf, L., Conroy-Beam, D., Asao, K., \& Buss, D. M. (20I6). Human emotions: An evolutionary psychological perspective. Emotion Review, 8(2), I73-I86.

Anderson, C., Hildreth, J. A. D., \& Howland, L. (2015). Is the desire for status a fundamental human motive? A review of the empirical literature. Psychological Bulletin, I4I(3), 574.

Anderson, C., Hildreth, J. A. D., \& Sharps, D. L. (2020). The Possession of High Status Strengthens the Status Motive. Personality and Social Psychology Bulletin, 46(I2), I712-I723.

Anderson, C., John, O. P., Keltner, D., \& Kring, A. M. (200I). Who attains social status? Effects of personality and physical attractiveness in social groups. Journal of personality and social psychology, 8I(I), II6.

Anderson, C., Srivastava, S., Beer, J. S., Spataro, S. E., \& Chatman, J. A. (2006). Knowing your place: self-perceptions of status in face-to-face groups. Journal of personality and social psychology, 9I(6), I094.

Boehm, C. (1999). Hierarchy in the forest: The evolution of egalitarian behavior. London, UK: Harvard University Press.

Boehm, C. (20I2). Ancestral hierarchy and conflict. Science, 336(6083), 844-847.

Boucher, J. D., \& Carlson, G. E. (I980). Recognition of facial expression in three cultures. Journal of cross-cultural psychology, II(3), 263-280.

Brown, D. E. (I99I). Human universals. New York, NY: McGraw-Hill.

Buss, D. M. (I990). The evolution of anxiety and social exclusion. Journal of Social and Clinical Psychology, 9(2), I96201.

Buss, D. M. (1997). Human social motivation in evolutionary perspective: Grounding terror management theory. Psychological Inquiry, 8(I), 22-26.

Buss, D. M., Durkee, P. K., Shackelford, T. K., Bowdle, B. F., Schmitt, D. P., Brase, G. L., ... \& Trofimova, I. (2020). Human status criteria: Sex differences and similarities across I4 nations. Journal of Personality and Social Psychology.

Case, C. R., \& Maner, J. K. (20I4). Divide and conquer: When and why leaders undermine the cohesive fabric of their group. Journal of personality and social psychology, IO7(6), I033.

Chapais, B. (20I5). Competence and the evolutionary origins of status and power in humans. Human Nature, 26(2), I6I-I83.

Chase, I. D. (1974). Models of hierarchy formation in animal societies. Behavioral Science, 19(6), 374-382.

Cheng, J. T. (2020). Dominance, prestige, and the role of leveling in human social hierarchy and equality. Current opinion in psychology, 33, 238-244.

Cheng, J. T., Tracy, J. L., \& Henrich, J. (20I0). Pride, personality, and the evolutionary foundations of human social status. Evolution and Human Behavior, 3I(5), 334-347.

Cheng, J. T., Tracy, J. L., Foulsham, T., Kingstone, A., \& Henrich, J. (2013). Two ways to the top: evidence that dominance and prestige are distinct yet viable avenues to social rank and influence. Journal of personality and social psychology, IO4(I), I03.

Cohen-Charash, Y., \& Larson, E. C. (20I7). What is the nature of envy? In R. H. Smith, U. Merlone, \& M. K. Duffy (Eds.), Envy at work and in organizations (pp. I-37). New York, NY: Oxford University Press.

Cohen, A. S., Chun, R., \& Sznycer, D. (2020). Do pride and shame track the evaluative psychology of audiences? Preregistered replications of Sznycer et al. (2016, 20I7). Royal Society open science, 7(5), I9I922.

Cosmides, L., \& Tooby, J. (2000). Evolutionary psychology and the emotions. Handbook of emotions, 2(2), 9I-II5.

Cowlishaw, G., \& Dunbar, R. I. (I99I). Dominance rank and mating success in male primates. Animal Behaviour, 4I(6), IO45-IO56.

Crusius, J., Gonzalez, M. F., Lange, J., \& Cohen-Charash, Y. (2020). Envy: An adversarial review and comparison of two competing views. Emotion Review, I2(I), 3-2I.

de Bruyn, E. H., Cillessen, A. H., \& Weisfeld, G. E. (20I2). Dominance-popularity status, behavior, and the emergence of sexual activity in young adolescents. Evolutionary psychology, IO(2), I4747049I20I000209.

de Waal, F. (I982). Chimpanzee politics: Sex and power among apes London. UK: Jonathan Cape.

Digman, J. M. (1990). Personality structure: Emergence of the five-factor model. Annual review of psychology, $4 \mathrm{I}(\mathrm{I})$, 4I7-440.

Durkee, P. K., Goetz, A. T., \& Lukaszewski, A. W. (20I8). Formidability assessment mechanisms: Examining their speed and automaticity. Evolution and Human Behavior, 39(2), I70-I78.

Durkee, P. K., Lukaszewski, A. W., \& Buss, D. M. (2019). Pride and shame: Key components of a culturally universal status management system. Evolution and Human Behavior, 4O(5), 470-478. 
Durkee, P. K., Lukaszewski, A. W., \& Buss, D. M. (2020). Psychological foundations of human status allocation. Proceedings of the National Academy of Sciences, II7(35), 21235-2124I.

Durkee, P., Lukaszewski, A., \& Buss, D. M. (202I, April 20). Status foundations: Further consideration of the role of 'dominance' and the relative importance of cost infliction and benefit generation. https://doi.org/I0.31234/osf.io/4gvt5

Durkee, P., Lukaszewski, A., von Rueden, C., Gurven, M., Buss, D. M., \& Tucker-Drob, E. M. (2020, July 24). Niche diversity predicts personality structure across II5 nations. https://doi.org/I0.31234/osf.io/93qmp

Ekman, P., \& Friesen, W. V. (1986). A new pan-cultural facial expression of emotion. Motivation and emotion, Io(2), I59-I68.

Fieder, M., Huber, S., \& Bookstein, F. L. (2OII). Socioeconomic status, marital status and childlessness in men and women: an analysis of census data from six countries. Journal of Biosocial Science, 43(5), 619.

Fischer, A. H., \& Roseman, I. J. (2007). Beat them or ban them: the characteristics and social functions of anger and contempt. Journal of personality and social psychology, 93(I), I03.

Fischer, A., \& Giner-Sorolla, R. (2016). Contempt: Derogating others while keeping calm. Emotion Review, 8(4), 346357.

Fiske, A. P. (2020). The lexical fallacy in emotion research: Mistaking vernacular words for psychological entities. Psychological review, I27(I), 95.

Fiske, S. T. (2015). Intergroup biases: A focus on stereotype content. Current opinion in behavioral sciences, 3, 45-50.

Franz, M., McLean, E., Tung, J., Altmann, J., \& Alberts, S. C. (2015). Self-organizing dominance hierarchies in a wild primate population. Proceedings of the Royal Society B: Biological Sciences, 282(I8I4), 20151512.

Garfield, Z. H., \& Hagen, E. H. (2020). Investigating evolutionary models of leadership among recently settled Ethiopian hunter-gatherers. The Leadership Quarterly, 3I(2), I0I290.

Garfield, Z. H., Hubbard, R. L., \& Hagen, E. H. (2019). Evolutionary models of leadership. Human Nature, 3O(I), 2358.

Garfield, Z. H., Syme, K. L., \& Hagen, E. H. (2020). Universal and variable leadership dimensions across human societies. Evolution and Human Behavior, 4I(5), 397-4I4.

Gervais, M. M., \& Fessler, D. M. (2017). On the deep structure of social affect: Attitudes, emotions, sentiments, and the case of" contempt". Behavioral and Brain Sciences, 40.

Gilbert, P. (200I). Evolution and social anxiety: The role of attraction, social competition, and social hierarchies. Psychiatric Clinics, 24(4), 723-75I.

Gintis, H., van Schaik, C., Boehm, C., Chapais, B., Flack, J. C., Pagel, M., ... \& Boehm, C. (2015). Zoon politikon: The evolutionary origins of human political systems. Current Anthropology, 56(3), 340-34I.

Griskevicius, V., Goldstein, N. J., Mortensen, C. R., Cialdini, R. B., \& Kenrick, D. T. (2006). Going along versus going alone: when fundamental motives facilitate strategic (non) conformity. Journal of personality and social psychology, 9I(2), 28I.

Grosz, M. P., Leckelt, M., \& Back, M. D. (2020). Personality predictors of social status attainment. Current opinion in psychology, 33, 52-56.

Gurven, M., Von Rueden, C., Massenkoff, M., Kaplan, H., \& Lero Vie, M. (2013). How universal is the Big Five? Testing the five-factor model of personality variation among forager-farmers in the Bolivian Amazon. Journal of personality and social psychology, IO4(2), 354.

Henrich, J., \& Gil-White, F. J. (200I). The evolution of prestige: Freely conferred deference as a mechanism for enhancing the benefits of cultural transmission. Evolution and human behavior, 22(3), 165-196.

Henrich, J., Chudek, M., \& Boyd, R. (2015). The Big Man Mechanism: how prestige fosters cooperation and creates prosocial leaders. Philosophical Transactions of the Royal Society B: Biological Sciences, 370(1683), 20150013.

Hill, S. E., \& Buss, D. M. (2006). Envy and positional bias in the evolutionary psychology of management. Managerial and Decision Economics, 27(2-3), I3I-I43.

Hill, S.E., \& Buss, D.M. (2008). The evolutionary psychology of envy. In R. Smith (Ed.), The psychology of envy (pp. 6o-70) New York: Guilford.

Hopcroft, R. L. (2006). Sex, status, and reproductive success in the contemporary United States. Evolution and Human Behavior, 27(2), IO4-I20.

Hopcroft, R. L. (2015). Sex differences in the relationship between status and number of offspring in the contemporary US. Evolution and Human Behavior, 36(2), I46-I5I.

Hopcroft, R. L. (202I). High income men have high value as long-term mates in the US: personal income and the probability of marriage, divorce, and childbearing in the US. Evolution and Human Behavior.

Hutcherson, C. A., \& Gross, J. J. (20II). The moral emotions: A social-functionalist account of anger, disgust, and contempt. Journal of personality and social psychology, IOO(4), 719. 
Issa, F. A., Adamson, D. J., \& Edwards, D. H. (1999). Dominance hierarchy formation in juvenile crayfish Procambarus clarkii. Journal of Experimental Biology, 202(24), 3497-3506.

Jaeggi, A. V., Blackwell, A. D., von Rueden, C., Trumble, B., Stieglitz, J., Garcia, A., ... \& Gurven, M. (2020). Relative wealth and inequality associate with health in a small-scale subsistence society. medRxiv.

Keltner, D. (1995). Signs of appeasement: Evidence for the distinct displays of embarrassment, amusement, and shame. Journal of Personality and Social Psychology, 68(3), 44I.

Keltner, D., \& Harker, L. (1998). The forms and functions of the non- verbal signal of shame. In P. Gilbert \& B. Andrews (Eds.), Shame: Interpersonal behavior, psychopathology, and culture (pp. 78-98). Oxford, England: Oxford University Press.

Keltner, D., Young, R. C., \& Buswell, B. N. (1997). Appeasement in human emotion, social practice, and personality. Aggressive Behavior, 23(5), 359-374.

Kenrick, D. T., Neuberg, S. L., Griskevicius, V., Becker, D. V., \& Schaller, M. (20I0). Goal-driven cognition and functional behavior: The fundamental-motives framework. Current Directions in Psychological Science, I9(I), 63-67.

Ko, A., Pick, C. M., Kwon, J. Y., Barlev, M., Krems, J. A., Varnum, M. E., ... \& Kenrick, D. T. (2020). Family matters: Rethinking the psychology of human social motivation. Perspectives on Psychological Science, 15(I), I73-20I.

Kyl-Heku, L. M., \& Buss, D. M. (1996). Tactics as units of analysis in personality psychology: An illustration using tactics of hierarchy negotiation. Personality and Individual Differences, 2I(4), 497-5I7.

Lee, K., \& Ashton, M. C. (2004). Psychometric properties of the HEXACO personality inventory. Multivariate behavioral research, 39(2), 329-358.

Lerner, J. S., \& Keltner, D. (200I). Fear, anger, and risk. Journal of personality and social psychology, 8I(I), I46.

Li, J., \& Fischer, K. W. (2007). Respect as a positive self-conscious emotion in European Americans and Chinese. In J. L. Tracy, R. W. Robins \& J. P. Tangney (Eds.), The self-conscious emotions: Theory and research (pp. 224242). New York: Guilford Press.

Lukaszewski, A. W. (202I). Evolutionary perspectives on the mechanistic underpinnings of personality. In J. F. Rauthmann (Ed.), The handbook of personality dynamics and processes. San Diego, CA: Elsevier Press.

Lukaszewski, A. W., Gurven, M., von Rueden, C. R., \& Schmitt, D. P. (20I7). What explains personality covariation? A test of the socioecological complexity hypothesis. Social Psychological and Personality Science, 8(8), 943952.

Lukaszewski, A. W., Lewis, D. M., Durkee, P. K., Sell, A. N., Sznycer, D., \& Buss, D. M. (2020). An adaptationist framework for personality science. European Journal of Personality, 34(6), II5I-II74.

Lukaszewski, A. W., Simmons, Z. L., Anderson, C., \& Roney, J. R. (2016). The role of physical formidability in human social status allocation. Journal of Personality and Social Psychology, IIO(3), 385.

Majolo, B., Lehmann, J., de Bortoli Vizioli, A., \& Schino, G. (2012). Fitness-related benefits of dominance in primates. American journal of physical anthropology, I47(4), 652-66o.

Maner, J. K., \& Mead, N. L. (20I0). The essential tension between leadership and power: when leaders sacrifice group goals for the sake of self-interest. Journal of personality and social psychology, 99(3), 482.

Maner, J. K., Kenrick, D. T., Becker, D. V., Robertson, T. E., Hofer, B., Neuberg, S. L., ... \& Schaller, M. (2005). Functional projection: How fundamental social motives can bias interpersonal perception. Journal of personality and social psychology, 88(I), 63.

Marsh, A. A., \& Ambady, N. (2007). The influence of the fear facial expression on prosocial responding. Cognition and Emotion, 2I(2), 225-247.

Marsh, A. A., Ambady, N., \& Kleck, R. E. (2005). The effects of fear and anger facial expressions on approach-and avoidance-related behaviors. Emotion, $5(\mathrm{I})$, II9.

Martens, J. P., Tracy, J. L., \& Shariff, A. F. (2012). Status signals: Adaptive benefits of displaying and observing the nonverbal expressions of pride and shame. Cognition \& Emotion, 26(3), 390-406.

Matsumoto, D., \& Ekman, P. (2004). The relationship among expressions, labels, and descriptions of contempt. Journal of personality and social psychology, 87(4), 529.

McCrae, R. R., \& Costa, P. T. (1987). Validation of the five-factor model of personality across instruments and observers. Journal of personality and social psychology, 52(I), 8I.

Mead, N. L., \& Maner, J. K. (2012). On keeping your enemies close: Powerful leaders seek proximity to ingroup power threats. Journal of Personality and Social Psychology, IO2(3), 576.

Meese, G. B., \& Ewbank, R. (1973). The establishment and nature of the dominance hierarchy in the domesticated pig. Animal behaviour, 2I(2), 326-334.

Miceli, M., \& Castelfranchi, C. (2007). The envious mind. Cognition and emotion, 2I(3), 449-479.

Mischel, W., \& Shoda, Y. (1995). A cognitive-affective system theory of personality: reconceptualizing situations, dispositions, dynamics, and invariance in personality structure. Psychological review, IO2(2), 246. 
Moran, S., \& Schweitzer, M. E. (2008). When better is worse: Envy and the use of deception. Negotiation and Conflict Management Research, I(I), 3-29.

Nesse, R. M. (1990). Evolutionary explanations of emotions. Human nature, I(3), $26 \mathrm{I}-289$.

Öhman, A., \& Mineka, S. (200I). Fears, phobias, and preparedness: toward an evolved module of fear and fear learning. Psychological review, Io8(3), 483.

Öhman, A., \& Mineka, S. (2003). The malicious serpent: Snakes as a prototypical stimulus for an evolved module of fear. Current directions in psychological science, I2(I), 5-9.

Onu, D., Kessler, T., \& Smith, J. R. (2016). Admiration: A conceptual review. Emotion Review, 8(3), 218-230.

Park, J., Kitayama, S., Markus, H. R., Coe, C. L., Miyamoto, Y., Karasawa, M., ... \& Ryff, C. D. (2013). Social status and anger expression: the cultural moderation hypothesis. Emotion, I3(6), II22.

Parrott, W. G., \& Smith, R. H. (1993). Distinguishing the experiences of envy and jealousy. Journal of personality and social psychology, 64(6), 906.

Patton, J. (2000). Reciprocal altruism and warfare. In L. Cronk, W. Irons, \& N. Chagnon (Eds.), Adaptation and human behavior: An anthropological perspective (pp. 4I7-436). Hawthorne, NY: Aldine de Gruyter.

Price, M. E., \& Van Vugt, M. (2014). The evolution of leader-follower reciprocity: the theory of service-for-prestige. Frontiers in human neuroscience, 8,363 .

Redhead, D. J., Cheng, J. T., Driver, C., Foulsham, T., \& O'Gorman, R. (2019). On the dynamics of social hierarchy: A longitudinal investigation of the rise and fall of prestige, dominance, and social rank in naturalistic task groups. Evolution and Human Behavior, 4O(2), 222-234.

Reed, L. I., \& DeScioli, P. (2017). Watch out! How a fearful face adds credibility to warnings of danger. Evolution and Human Behavior, 38(4), 490-495.

Robertson, T. E., Sznycer, D., Delton, A. W., Tooby, J., \& Cosmides, L. (20I8). The true trigger of shame: Social devaluation is sufficient, wrongdoing is unnecessary. Evolution and Human Behavior, 39(5), 566-573.

Rozin, P., Lowery, L., Imada, S., \& Haidt, J. (1999). The CAD triad hypothesis: a mapping between three moral emotions (contempt, anger, disgust) and three moral codes (community, autonomy, divinity). Journal of personality and social psychology, 76(4), 574 .

Schaubroeck, J., \& Lam, S. S. (2004). Comparing lots before and after: Promotion rejectees' invidious reactions to promotees. Organizational Behavior and Human Decision Processes, 94(I), 33-47.

Sell, A., Cosmides, L., \& Tooby, J. (2014). The human anger face evolved to enhance cues of strength. Evolution and Human Behavior, 35(5), 425-429.

Sell, A., Cosmides, L., Tooby, J., Sznycer, D., Von Rueden, C., \& Gurven, M. (2009). Human adaptations for the visual assessment of strength and fighting ability from the body and face. Proceedings of the Royal Society B: Biological Sciences, 276(I656), 575-584.

Sell, A., Sznycer, D., Al-Shawaf, L., Lim, J., Krauss, A., Feldman, A., ... \& Tooby, J. (2017). The grammar of anger: Mapping the computational architecture of a recalibrational emotion. Cognition, I68, IIO-I28.

Shariff, A. F., \& Tracy, J. L. (2009). Knowing who's boss: Implicit perceptions of status from the nonverbal expression of pride. Emotion, 9(5), 63I.

Shariff, A. F., Tracy, J. L., \& Markusoff, J. L. (20I2). (Implicitly) judging a book by its cover: The power of pride and shame expressions in shaping judgments of social status. Personality and Social Psychology Bulletin, 38(9), II78-II93.

Smaldino, P. E., Lukaszewski, A., von Rueden, C., \& Gurven, M. (2019). Niche diversity can explain cross-cultural differences in personality structure. Nature Human Behaviour, 3(12), 1276-1283.

Smith, R. H., \& Kim, S. H. (2007). Comprehending envy. Psychological bulletin, I33(I), 46.

Steckler, C., \& Tracy, J. L. (20I4). The emotional underpinnings of social status. In J. T. Cheng, J. L. Tracy, \& C. Anderson (Eds.), The psychology of social status (pp. 20I-224). New York, NY: Springer.

Susskind, J. M., Lee, D. H., Cusi, A., Feiman, R., Grabski, W., \& Anderson, A. K. (2008). Expressing fear enhances sensory acquisition. Nature neuroscience, $I I(7), 843$.

Sznycer, D. (2019). Forms and functions of the self-conscious emotions. Trends in cognitive sciences, 23(2), I43-157.

Sznycer, D., \& Cohen, A. S. (202I). How pride works. Evolutionary Human Sciences, 3.

Sznycer, D., \& Lukaszewski, A. W. (2019). The emotion-valuation constellation: Multiple emotions are governed by a common grammar of social valuation. Evolution and Human Behavior, 4O(4), 395-404.

Sznycer, D., Al-Shawaf, L., Bereby-Meyer, Y., Curry, O. S., De Smet, D., Ermer, E., ... \& Tooby, J. (20I7). Crosscultural regularities in the cognitive architecture of pride. Proceedings of the National Academy of Sciences, II4(8), I874-I879.

Sznycer, D., Cosmides, L., \& Tooby, J. (2017). Adaptationism carves emotions at their functional joints. Psychological Inquiry, 28(I), 56-62. 
Sznycer, D., Tooby, J., Cosmides, L., Porat, R., Shalvi, S., \& Halperin, E. (20I6). Shame closely tracks the threat of devaluation by others, even across cultures. Proceedings of the National Academy of Sciences, II3(IO), 26252630.

Sznycer, D., Xygalatas, D., Agey, E., Alami, S., An, X. F., Ananyeva, K. I., ... \& Tooby, J. (2018). Cross-cultural invariances in the architecture of shame. Proceedings of the National Academy of Sciences, I15(39), 9702-9707.

Sznycer, D., Xygalatas, D., Alami, S., An, X. F., Ananyeva, K. I., Fukushima, S., ... \& Tooby, J. (2018). Invariances in the architecture of pride across small-scale societies. Proceedings of the National Academy of Sciences, II5(33), $8322-8327$.

Takahashi, H., Kato, M., Matsuura, M., Mobbs, D., Suhara, T., \& Okubo, Y. (2009). When your gain is my pain and your pain is my gain: neural correlates of envy and schadenfreude. Science, 323(5916), 937-939.

Tooby, J., \& Cosmides, L. (1990). The past explains the present: Emotional adaptations and the structure of ancestral environments. Ethology and sociobiology, II(4-5), 375-424.

Tooby, J., Cosmides, L., Sell, A., Lieberman, D. \& Sznycer, D. (2008) Internal regulatory variables and the design of human motivation: A computational and evolutionary approach. In: Handbook of approach and avoidance motivation, ed. A. J. Elliot, pp. 25I-7I. Erlbaum.

Toscano, H., Schubert, T. W., Dotsch, R., Falvello, V., \& Todorov, A. (2016). Physical strength as a cue to dominance: A data-driven approach. Personality and Social Psychology Bulletin, 42(12), I603-1616.

Tracy, J. L., \& Matsumoto, D. (2008). The spontaneous expression of pride and shame: Evidence for biologically innate nonverbal displays. Proceedings of the National Academy of Sciences, I05(33), II655-II660.

Tracy, J. L., \& Robins, R. W. (2007). The prototypical pride expression: development of a nonverbal behavior coding system. Emotion, 7(4), 789 .

Tracy, J. L., \& Robins, R. W. (2008). The automaticity of emotion recognition. Emotion, 8(I), 8I.

Tracy, J. L., \& Robins, R. W. (2008). The nonverbal expression of pride: evidence for cross-cultural recognition. Journal of personality and social psychology, 94(3), 516.

Tracy, J. L., Shariff, A. F., Zhao, W., \& Henrich, J. (2013). Cross-cultural evidence that the nonverbal expression of pride is an automatic status signal. Journal of Experimental Psychology: General, I42(I), I63.

van Kleef, G. A., \& Lange, J. (2020). How hierarchy shapes our emotional lives: effects of power and status on emotional experience, expression, and responsiveness. Current opinion in psychology, 33, I48-153.

van Schaik, Carel P., S. A. Pandit, and E. R. Vogel. 2006. Toward a general model for male-male coalitions in primate groups. In Cooperation in primates and humans: mechanisms and evolution. P. M. Kappeler and Carel P. van Schaik, eds. pp. 15I-I7I. Berlin: Springer.

Van Vugt, M., \& Tybur, J. M. (2015). The evolutionary foundations of hierarchy: Status, dominance, prestige, and leadership. In D. M. Buss (Ed.), The handbook of evolutionary psychology (2nd ed., pp. 788 - 809). Hoboken, NJ: Wiley.

von Rueden, C. (20I4). The roots and fruits of social status in small-scale human societies. In J. T. Cheng, J. L. Tracy, \& C. Anderson (Eds.), The psychology of social status (pp. 179-200). Springer, New York, NY.

von Rueden, C., Gurven, M., \& Kaplan, H. (2008). The multiple dimensions of male social status in an Amazonian society. Evolution and Human Behavior, 29(6), 402-415.

von Rueden, C., \& Jaeggi, A. V. (20I6). Men's status and reproductive success in 33 nonindustrial societies: Effects of subsistence, marriage system, and reproductive strategy. Proceedings of the National Academy of Sciences, II3(39), IO824-IO829.

von Rueden, C.., Redhead, D., O'Gorman, R., Kaplan, H., \& Gurven, M. (2019). The dynamics of men's cooperation and social status in a small-scale society. Proceedings of the Royal Society B, 286(1908), 20191367.

von Rueden, C., Gurven, M., \& Kaplan, H. (20II). Why do men seek status? Fitness payoffs to dominance and prestige. Proceedings of the Royal Society B: Biological Sciences, 278(1715), 2223-2232.

Whalen, P. J., Shin, L. M., McInerney, S. C., Fischer, H., Wright, C. I., \& Rauch, S. L. (20oI). A functional MRI study of human amygdala responses to facial expressions of fear versus anger. Emotion, I(I), 70.

Wiessner, P. (2019). Collective Action for War and for Peace. Current Anthropology, 6o(2).

Witkower, Z., Mercadante, E. J., \& Tracy, J. L. (2020). How affect shapes status: Distinct emotional experiences and expressions facilitate social hierarchy navigation. Current opinion in psychology, 33, 18-22.

Wojciszke, B., Abele, A. E., \& Baryla, W. (2009). Two dimensions of interpersonal attitudes: Liking depends on communion, respect depends on agency. European Journal of Social Psychology, 39(6), 973-990.

Wrangham, R. W. (202I). Targeted conspiratorial killing, human self-domestication and the evolution of groupishness. Evolutionary Human Sciences, 3. 
Table I. Overview of the ways in which focal emotions may aid in solving adaptive challenges posed by hierarchy navigation.

\begin{tabular}{|c|c|c|c|c|c|c|c|c|}
\hline & Pride & Shame & Envy & Admiration & Respect & Contempt & Anger & Fear \\
\hline Pursuing status & $\begin{array}{l}\text { Motivate and } \\
\text { reward } \\
\text { pursuit of } \\
\text { status- } \\
\text { enhancing } \\
\text { skills and } \\
\text { characteristics }\end{array}$ & $\begin{array}{l}\text { Avoid and } \\
\text { conceal } \\
\text { status- } \\
\text { decreasing } \\
\text { events and } \\
\text { characteristics }\end{array}$ & $\begin{array}{c}\text { Identify } \\
\text { competitors } \\
\text { and motivate } \\
\text { competition }\end{array}$ & $\begin{array}{c}\text { Identify } \\
\text { models and } \\
\text { valued skills, } \\
\text { motivate } \\
\text { imitation and } \\
\text { emulation }\end{array}$ & $\begin{array}{l}\text { Identify status } \\
\text { criteria }\end{array}$ & NA & NA & $\begin{array}{c}\text { Prevent } \\
\text { overly risky } \\
\text { status pursuit }\end{array}$ \\
\hline $\begin{array}{l}\text { Leveraging } \\
\text { status }\end{array}$ & $\begin{array}{l}\text { Upregulate } \\
\text { entitlement, } \\
\text { signal status } \\
\text { to others }\end{array}$ & NA & NA & NA & NA & $\begin{array}{l}\text { Downregulate } \\
\text { cooperation } \\
\text { with low } \\
\text { value others }\end{array}$ & $\begin{array}{l}\text { Bargain for } \\
\text { better } \\
\text { treatment, } \\
\text { more benefits }\end{array}$ & $\begin{array}{l}\text { Prevent } \\
\text { behaviors that } \\
\text { could lead to } \\
\text { leveling } \\
\text { attempts }\end{array}$ \\
\hline $\begin{array}{l}\text { Maintaining } \\
\text { status }\end{array}$ & $\begin{array}{l}\text { Motivate } \\
\text { maintenance } \\
\text { and } \\
\text { improvement } \\
\text { of status } \\
\text { criteria }\end{array}$ & $\begin{array}{l}\text { Conceal and } \\
\text { avoid status- } \\
\text { decreasing } \\
\text { characteristics }\end{array}$ & $\begin{array}{l}\text { Facilitate } \\
\text { continued } \\
\text { competition }\end{array}$ & $\begin{array}{c}\text { Facilitate } \\
\text { continued } \\
\text { emulation } \\
\text { and imitation }\end{array}$ & $\begin{array}{l}\text { Avoid cost- } \\
\text { infliction } \\
\text { from higher- } \\
\text { status others }\end{array}$ & $\begin{array}{c}\text { Avoid } \\
\text { cooperation } \\
\text { with low- } \\
\text { value partners }\end{array}$ & $\begin{array}{l}\text { Punish } \\
\text { challengers, } \\
\text { recalibrate } \\
\text { devaluers }\end{array}$ & $\begin{array}{l}\text { Prevent } \\
\text { behaviors that } \\
\text { could lead to } \\
\text { leveling } \\
\text { attempts }\end{array}$ \\
\hline $\begin{array}{l}\text { Mitigating } \\
\text { status loss }\end{array}$ & NA & $\begin{array}{l}\text { Coordinate } \\
\text { avoidance, } \\
\text { appeasement }\end{array}$ & $\begin{array}{l}\text { Derogate or } \\
\text { undermine } \\
\text { rivals }\end{array}$ & NA & NA & NA & NA & $\begin{array}{l}\text { Prevent } \\
\text { behaviors that } \\
\text { could lead to } \\
\text { further costs }\end{array}$ \\
\hline $\begin{array}{l}\text { Tracking and } \\
\text { allocating status }\end{array}$ & NA & NA & $\begin{array}{c}\text { Recognize } \\
\text { potential } \\
\text { status } \\
\text { differential }\end{array}$ & $\begin{array}{c}\text { Recognize } \\
\text { and allocate } \\
\text { status to } \\
\text { useful models }\end{array}$ & $\begin{array}{c}\text { Recognize } \\
\text { social value } \\
\text { and facilitate } \\
\text { status } \\
\text { conferral }\end{array}$ & $\begin{array}{l}\text { Recognize } \\
\text { low social } \\
\text { value traits or } \\
\text { individuals }\end{array}$ & NA & NA \\
\hline $\begin{array}{l}\text { Interacting with } \\
\text { higher-status } \\
\text { others }\end{array}$ & NA & NA & $\begin{array}{c}\text { Facilitate } \\
\text { competition }\end{array}$ & $\begin{array}{l}\text { Facilitate } \\
\text { ingratiation, } \\
\text { learning, and } \\
\text { emulation }\end{array}$ & $\begin{array}{l}\text { Produce } \\
\text { deference }\end{array}$ & NA & NA & $\begin{array}{l}\text { Recognize } \\
\text { and prevent } \\
\text { costs that } \\
\text { could be } \\
\text { imposed }\end{array}$ \\
\hline $\begin{array}{l}\text { Hierarchy } \\
\text { restructuring } \\
\text { and leveling }\end{array}$ & NA & NA & $\begin{array}{l}\text { Motivation to } \\
\text { tear down } \\
\text { others }\end{array}$ & NA & NA & $\begin{array}{l}\text { Recognize } \\
\text { high-status } \\
\text { others' low } \\
\text { personal } \\
\text { cooperative } \\
\text { value }\end{array}$ & $\begin{array}{l}\text { Motivate and } \\
\text { coordinate } \\
\text { aggressive } \\
\text { bargaining }\end{array}$ & NA \\
\hline
\end{tabular}

Note: See main text for relevant references. NA = emotion not expected to be reliably activated by cues of the given adaptive challenge. 